\title{
DYE EXTRACTION METHOD EVALUATION OF THE SEALING ABILITY OF THREE TYPES OF ENDODONTIC SEALERS
}

\author{
Engy M Kataia* and Mohamed M Kataia**
}

\begin{abstract}
This study aimed to: evaluate the sealing ability of AH Plus sealer, IRoot SP sealer, and Epiphany-Resilon root canal filling system by Dye extraction method.

Methods: 45 freshly extracted single rooted human teeth were instrumented with Revo-S; the sequence used was SC1, SC2, SU, AS30, AS35, and AS40 taper 0.06. The prepared specimens were then divided randomly into Negative controls $(n=9)$ and Positive controls $(n=9)$; the negative controls were completely covered with three layers of varnish, and the positive controls were enlarged, but not root filled. The remaining 27 teeth were then randomly divided into three groups of 9 teeth each according to the type of sealer used, as the following: Group 1 (AH Plus sealer), Group 2 (IRoot SP sealer), and Group 3 (Epiphany-Resilon root canal filling system). Apical leakage evaluation was done by dye extraction methods. Data were statistically analyzed.
\end{abstract}

Results: The positive control showed total dye absorbance of 5000, while negative control samples had a low absorbance of 75. The mean absorbance values were 370, 315, and 400 for Group 1 (AH Plus), Group 2 (IRoot SP), and Group3 (Epiphany-Resilon root canal filling system) respectively.

Conclusion: The three tested sealers had the similar capability in apical sealing.

KEY WORDS: Dye extraction, Sealing Ability, IRoot SP, Epiphany-Resilon

\section{INTRODUCTION}

Adhesion of root canal filling material to dentinal walls is important in both static and dynamic situations. In a static situation, it should eliminate any space that allows the percolation of fluids between the filling and the wall ${ }^{(1)}$. In a dynamic situation, it is needed to resist dislodgement of the filling during subsequent manipulation ${ }^{(2)}$.

It has been indicated that both apical and coronal leakage may lead to loss of more endodontically treated teeth than other failures of endodontic therapy. To minimize the seal of the root canal system,

* Researcher in restorative and dental materials department, National Research Center, Cairo, Egypt

** Lecturer in Endodontic department, EL Minia University, Egypt 
sealers are used to eliminate the interface between gutta-percha and dentinal walls ${ }^{(3)}$. The sealer plays an important role in reducing microleakage ${ }^{(4)}$.

Many types and brands of sealers are available, which may be broadly classified into zinc oxideeugenol based, calcium hydroxide based, epoxy resin, and glass ionomer cement. Numerous studies have been carried out to compare sealing property of various sealers, but there is hardly any common consensus. Some studies showed that the resin-based sealer provided a better seal than other sealers ${ }^{(3,5)}$.

Recently, a new sealer has been introduced by the School of Dental Sciences, Universiti Sains Malaysia, Malaysia, known as Nano-Hydroxyapatite (Nano- HA) sealer ${ }^{(6)}$.

Micro-leakage, as related to endodontics, refers to the movement of fluid and microorganisms along the interface of the dentinal walls and the root filling material or through voids within the root filling material ${ }^{(7)}$. Many investigators compared the sealing ability of the intact root-canal filling ${ }^{(8,9)}$.

Using tooth immersion in various types of dyes (eosin, methylene blue, black India ink, Procion brilliant blue, and others), reported for the first time by Grossman in 1939, is perhaps most widely used, mainly because it is easy to perform. The phenomenon of capillarity is of utmost importance in this passive method used mainly for assessing apical leakage, as the tooth apex is submerged in the dye that penetrates through any space between the canal walls and filling material ${ }^{(10)}$.

Thus the purpose of this study aimed to evaluate the sealing ability of AH Plus sealer, IRoot SP sealer, and Epiphany-Resilon root canal filling system by dye extraction methods.

\section{MATERIAL AND METHODS}

\section{Selection of the teeth used in the study}

45 freshly extracted sound human single rooted teeth (maxillary anterior teeth) with no sign of cracks or structural anomalies under light microscope were collected. A solution $5.25 \%$ sodium hypochlorite soaked into gauze was used to remove any soft tissue covering the root surface and any calculus was removed by the aid of ultrasonic scaler. The teeth were radiographed from the buccal and mesial aspects to visualize the root canal anatomy and ensure closed apices. Teeth were then stored in $0.1 \%$ thymol solution at room temperature until used. The selected teeth were decoronated with a diamond disk (D\&Z, Berlin, Germany) under water spray cooling to standardized root length of 16 $\mathrm{mm}$. The pulp tissues were removed with a barbed broach (Dentsply, Maillefer, Switzerland). A size $10 \mathrm{~K}$ type file (Dentsply, Maillefer, Tulsa, OK) was introduced into each root canal using a small back and forth motion to ensure patency.

\section{Specimen's preparation}

Working length was determined by placing a \#15 $\mathrm{K}$ file until the tip was just visible beyond the apex, after which $1 \mathrm{~mm}$ was subtracted from this and the length was recorded. All root canals were then prepared using the step down technique according to the specific manufacture's instruction, using Revo-S $\mathrm{S}^{\mathrm{TM}}$, the sequence used was $\mathrm{SC} 1, \mathrm{SC} 2, \mathrm{SU}$, AS30, AS35, and AS40 taper 0.06. The preparation was accomplished using (Root ZX II) ** torque control motor at the rotational speed $250 \mathrm{rpm} .2 \mathrm{ml}$ of $\mathrm{NaOCl}$ of $2.6 \%$ concentration was the irrigant solution used after each file. The specimens received a final rinse with $1 \mathrm{ml}$ 17\% EDTA solution ${ }^{* * *}$ in order to remove the smear layer then were rinsed with sterile water.

- Wood packer china.

${ }^{*}$ Micromega France

** J.MORITA MFG. CORP. 680 HIGASHIHAMA, MINAMI-CHO.

**** Dentsply, Latin America, Brazil 
Finally, the root canals were dried with paper point after completion of instrumentation. Teeth were divided into three main groups.

\section{Specimen's grouping}

The prepared specimens were then divided randomly into Negative controls $(\mathrm{n}=9)$ and Positive controls $(n=9)$; the negative controls were completely covered with three layers of varnish, and the positive controls were enlarged, but not root filled. The remaining 27 teeth were then randomly divided into three groups of 9 teeth each, to be filled as the following:

\section{Group 1(AH Plus sealer)}

Was filled with Size 40, 0.06 tapered guttapercha (DiaDent Group Int., Canada) with "AH Plus sealer" (Dentsply Detrey, GmbH, 78467, Konstanz, Germany).

A master cone Size 40, 0.06 tapered guttapercha was fitted to the working length and presence of tug-back was confirmed. AH Plus sealer was mixed according to manufacturer's instructions to a creamy consistency and applied into the canals using lentulo spiral (Dentsply-Caulk, Milford, DE, USA) which was inserted within $2 \mathrm{~mm}$ short of the working length. After placement and condensation of the master cone at the appropriate working length, accessory cones were placed and condensed using a finger spreader (Miltex, Inc., York, PA, USA). The excess of gutta- percha was removed with a heated instrument and condensed vertically with plugger (Nordent, USA) to the level of the canal orifice.

\section{Group 2 (IRoot SP)}

Was filled with Size 40, 0.06 tapered guttapercha (DiaDent Group Int., Canada) with calcium silicate phosphate based bio ceramic Nanocompositions Bio Aggregate "IRoot SP" (IBC, Canada).

A master cone Size 40, 0.06 tapered gutta-percha was fitted to the working length and presence of tug-back was confirmed. IRoot SP sealer was mixed according to manufacturer's instructions to a creamy consistency and applied into the canals using lentulo spiral (Dentsply-Caulk, Milford, DE, USA) which was inserted within $2 \mathrm{~mm}$ short of the working length. After placement and condensation of the master cone at the appropriate working length, accessory cones were placed and condensed using a finger spreader (Miltex, Inc., York, PA, USA). The excess of gutta- percha was removed with a heated instrument and condensed vertically with plugger (Nordent, USA) to the level of the canal orifice.

\section{Group 3 (Epiphany-Resilon root canal filling system)}

Was filled with Size 40, 0.06 EpiphanyResilon root canal filling system (Pentron Clinical Technologies LLC, Wallingford, CT, USA). First, the primer was inserted into the root canals and excess was removed with paper point (Dentsply Tulsa Dental Specialties). Subsequently, Epiphany sealer was mixed according to the manufacturer's instructions and inserted into the root canals with a lentulo spiral. Resilon master cone size 40 was placed into the root canal. Following the application of the sealer, inserting accessory cones dipped in Epiphany sealer and laterally condensing with a finger spreader completed root canal filling. Excess Resilon cones were removed with a heated instrument and condensed vertically with a plugger to the level of the canal orifice.

\section{Apical leakage evaluation (dye extraction methods)}

After obturation, the specimens were stored for 24 hour at $37^{\circ} \mathrm{C}$ and $100 \%$ humidity in an incubator to allow setting of the sealer. Then the specimens were covered with nail varnish, with the exception of the apical $1 \mathrm{~mm}$, and setting of the varnish was completed before dipping into $2 \%$ methylene blue. The teeth were then placed in vacuum chambers containing 2\% methylene blue and a vacuum of 7.98 $\mathrm{Pa}$ for 15 min was applied. Then the specimens were stored in a hermetic sealed vial containing $65 \%$ nitric acid for three days. The vials were then centrifuged 
at $14,000 \mathrm{rpm}$ for $5 \mathrm{~min}$ to separate gutta-percha debris from the extracted dye. Dye concentration in the supernatant solution was analyzed using an UVspectrophotometer (Shimadzu UV-160, Shimadzu Corp., Kyoto, Japan) at $550 \mathrm{~nm}$ using concentrated nitric acid as a blank ${ }^{(11)}$.

\section{Statistical Analysis}

The results were evaluated statistically using one-way analysis of variance (ANOVA). The significance level was set at $\mathrm{P} \leq 0.05$.

The positive control showed total dye absorbance, of 5000, while negative control samples had a low absorbance of 75, close to that of the blank (nitric acid), which had absorbance of 52 (Figure 1). The mean absorbance values were 370,315 , and 400 for Group 1 (AH Plus), Group 2 (IRoot SP), and Group 3 (Epiphany-Resilon root canal filling system) respectively. A one-way ANOVA test showed no significant difference among the experimental groups $(\mathrm{P}>0.05)$. (Table I).

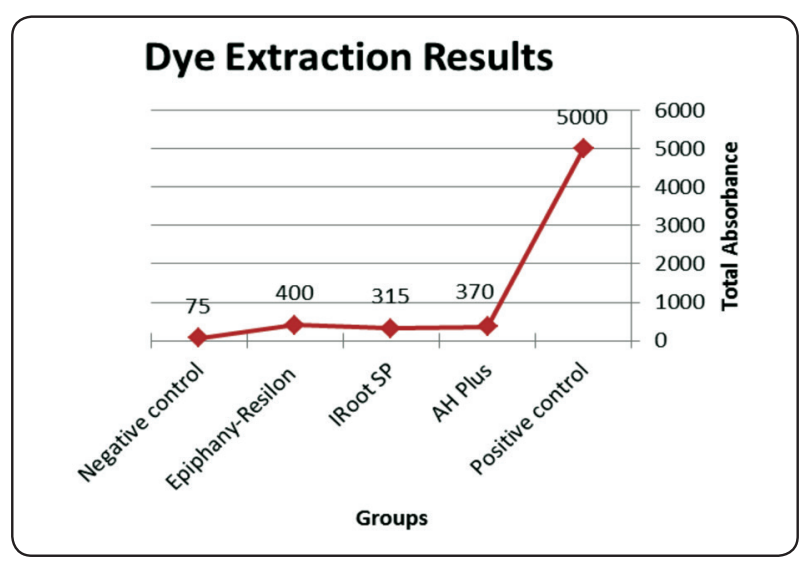

Fig. (1) A histogram showing the mean dye extraction results.
TABLE (1) Showing Evaluation of dye penetration using dye extraction method.

\begin{tabular}{|l|c|c|}
\hline Groups & Mean \pm SD & P value \\
\hline $\begin{array}{l}\text { Group 1 } \\
\text { (AH Plus) }\end{array}$ & $\mathbf{3 7 0} \pm \mathbf{3 3 . 9}$ & \\
\hline $\begin{array}{l}\text { Group2 } \\
\text { (IRoot SP) }\end{array}$ & $\mathbf{3 1 5} \pm \mathbf{5 5 . 6}$ & $\mathbf{P}>\mathbf{0 . 0 5 *}$ \\
\hline $\begin{array}{l}\text { Group3 } \\
\text { (Epiphany-Resilon root canal } \\
\text { filling system) }\end{array}$ & $\mathbf{4 0 0 \pm 6 1 . 2}$ & \\
\hline Positive control & $\mathbf{5 0 0 0} \pm \mathbf{2 9 0 . 1}$ & \\
\hline Negative control & $\mathbf{7 5} \pm \mathbf{7 . 9}$ & \\
\hline
\end{tabular}

"Non-significant ( $p>0.05)$

\section{DISCUSSION}

Root canal sealers are used in combination with core materials such as Gutta-percha cones. The sealer binds the cones together and obliterates the irregularities between the canal wall and the core material $^{(12)}$.

Dye penetration techniques are the most frequently used methods to evaluate the sealing ability of dental materials. These are commonly used because they are easy to complete and do not require sophisticated materials. Dye-extraction provides more reliable results because it measures all of the dye taken up in the $\operatorname{root}^{(13)}$.

The present study was aimed to evaluate the sealing ability of AH Plus sealer, IRoot SP sealer, and Epiphany-Resilon root canal filling system by dye extraction methods.

The results of the present study indicate that there was no significant difference in the sealing ability between the three tested sealers ( $p>0.05)$. The mean absorbance values were 370,315 , and 400 for Group 1 (AH Plus), Group 2 (IRoot SP), and Group 3 (Epiphany-Resilon root canal filling system) respectively. 
The reason for these results may be due to low solubility, small expansion, adhesion to dentin and a very good sealing ability ${ }^{(14)}$. Swelling of epoxy resin component of $\mathrm{AH}$ plus after water sorption may also increase the adaptability and dentinal penetration ${ }^{(15)}$.

AH Plus sealer is considered as a better penetration into the micro-irregularities because of its creep capacity and long setting time, which increases the mechanical interlocking between sealer and root dentin, and very good sealing ability $^{(14,15)}$.

IRoot SP sealer is composed of biocompatible and nontoxic materials that include calcium phosphate, calcium silicates, zirconium oxide, and calcium hydroxide. iRoot SP includes a similar composition to white mineral trioxide aggregate (MTA) material and has excellent physical properties, biocompatibility, and does not shrink during setting and hardens in the presence of water $^{(16)}$.

Epiphany-Resilon root canal filling system it utilizes a resinous obturating material and an adhesive resin sealer, creating a monoblock of dentin/adhesive/obturating material. The Resilon cones consist of is a vinyl polyester material with methacrylate polymer, glass filler particles, and opacifiers added. Its appearance and manipulation are similar to gutta-percha. Epiphany sealer consists of a self-etching primer that is used with a lightly filled dual-cured UDMA sealer/adhesive ${ }^{(17)}$.

These results were consonant with Zhang et al. (16) whom concluded that iRoot SP was equivalent to AH Plus sealer in apical sealing ability. In addition, iRoot SP was a suitable cement paste for use in the single-cone filling technique. Furthermore, Sagsen et al. ${ }^{(18)}$ assessed the push-out bond strengths of two new calcium silicate-based endodontic sealers MTA and iRoot SP and compared them with AH Plus in the root canals of extracted teeth and found that in the coronal specimens, there was no significant difference between the sealers. Ungor et al. ${ }^{(19)}$ stated that the Epiphany - Resilon combination was not superior to that of the AH Plus gutta percha combination.

Just as many studies have reported that AH Plus and Epiphany have equal sealing properties ${ }^{(20,21)}$. Still, other studies have found that the apical sealing ability of Epiphany was superior to AH Plus, having observed absolutely no apical leakage with the Epiphany sealer ${ }^{(22,23)}$. Such contradictory results may be caused by the different root canal preparation methods used in each study, or the different canal filling techniques and microleakage testing models.

On other hand Negative control samples in the present study had low dye absorbance (75) close to that of blank (nitric acid), which showed absorbance of 52. This small difference can be attributed to the yellowish color of teeth, whereas blank is colorless ${ }^{(13)}$, while the Positive control samples had the highest dye absorbance (5000) of all groups denoting the accuracy of the technique.

\section{CONCLUSIONS}

Based on the results of this study, the three tested sealers displayed nearly similar leakage pattern. Furthermore, the dye extraction technique is promising, rapid and can be performed using equipment that is available in most dental schools.

\section{REFERENCES}

1. Qrstavik D, Eriksen HM, Beyer-Olsen EM. Adhesive properties and leakage of root canal sealers in vitro. Int Endod J 1983; 16: 59-63.

2. Stewart GG. A comparative study of three root canal sealing agents (Part 1). Oral Surgery 1958; 11: 1029-41.

3. Timpawat S.Amornchat C. Trisuwan W. Bacterial Coronal Leakage after Obturation with Three Root Canal Sealers. J Endod 2001; 27:36- 39.

4. Canalda-Sahli C, Brau-Aguade E, Sentis-Vilalta J, Aguade-Bruix S. The apical seal of root canal sealing cements using a radionuclide detection technique. Int Endod J 1992; 25:250-6. 
5. Kataoka H, Yoshioka T, Suda H, Imai Y. Dentin bonding and sealing ability of a new root canal resin sealer. J Endod 2000;26: 230-5.

6. Salma B A, Aziza A D, Sam' an M M, Norhayati L, Adam H. Sealing ability of gutta-percha/Nano HA versus Resilon/ Epiphany after 20 months using an electrochemical model - an in vitro study. Braz J Oral Sci.2012; 11(3):387-91.

7. Leonard J.E,., Gutrnann J.L, Guo 1,Y. Apical and coronal seal of roots obturated with a dentine bonding agent and resin. Int Endod J 1996; 29:76-83.

8. Abramovitz I, Tagger M, Tamse A, Metzger Z. The effect of immediate vs. delayed post space preparation on the apical seal of a root canal filling: a study in an increasedsensitivity pressure-driven system. J Endod 2000; 26:435-9.

9. De Cleen M.J. The relationship between the root canal filling and post space preparation. Int Endod J 1993; 26:53- 8 .

10. Verissimo D.M, do Vale M.S. Methodologies for assessment of apical and coronal leakage of endodontic filling materials: a critical review. J Oral Scien 2006; 48: 93- 8 .

11. Kaya S, Ozer SY, Yavuz İ, Aydin H. Comparison of Dye Extraction or Dye Penetration Methods to Quantitatively Determine Microleakage of Three Different Root Canal Sealers. Dentistry 2011; 1:105.

12. Camilleri J, Mallia B. Evaluation of the dimensional changes of mineral trioxide aggregate sealer. Int Endod J 2011; 44:416 -24.

13. Hamad HA, Tordik PA, McClanahan SB. Furcation perforation repair comparing gray and white MTA: a dye extraction study. J Endod 2006; 32:337- 40.

14. Azar NG, Heidari M, Bahrami ZS, Shokri F. In vitro cytotoxicity of a new epoxy resin root canal sealer. J Endod 2000; 26:462-5.
15. Roggendorf M. Bayerisches Zahnärzteblatt. Sept. München Germany. Bavarian Dent J 2004: 32- 4.

16. Zhang w, Li Z, Peng B. Assessment of a new root canal sealer's apical sealing ability. Oral Surg Oral Med Oral Pathol Oral Radiol Endod 2009; 107: 79-82.

17. Richard S. Adhesive Dentistry and Endodontics. Part 2: Bonding in the Root Canal System -The Promise and the Problems: A Review. J Endod 2006; 32:1125-1134.

18. Sagsen B, Ustün Y, Demirbuga S, Pala K. Push-out bond strength of two new calcium silicate-based endodontic sealers to root canal dentine. Int Endod J. 2011:44; 1088-91.

19. Ungor M, Onay EO, Orucoglu H. Push-out bond strengths: the Epiphany-Resilon endodontic obturation system compared with different pairings of Epiphany, Resilon, AH Plus and guttapercha. Int Endod J2006; 39: 643- 47.

20. Hollanda AC, Estrela CR, Decurcio Dde A, Silva JA, Estrela C. Sealing ability of three commercial resin-based endodontic sealers. Gen Dent 2009; 57:368e73.

21. Williamson AE, Marker KL, Drake DR, Dawson DV, Walton RE. Resin-based versus gutta-percha-based root canal obturation: influence on bacterial leakage in an in vitro model system. Oral Surg Oral Med Oral Pathol Oral Radiol Endod 2009; 108:292 - 6.

22. Sagsen B, Er O, Kahraman Y, Orucoglu H. Evaluation of microleakage of roots filled with different techniques with a computerized fluid filtration technique. J Endod 2006; 32: $1168-70$.

23. Dultra F, Barroso JM, Carrasco LD, Capelli A, Guerisoli DM, Pecora JD. Evaluation of apical microleakage of teeth sealed with four different root canal sealers. J Appl Oral Sci 2006; 14: 341-5. 